\title{
The possible contribution of the amygdala to memory
}

\author{
R. Babinsky ${ }^{1,4}$, P. Calabrese ${ }^{1,2}$, H.F. Durwen ${ }^{2}$, H.J. Markowitsch', \\ D. Brechtelsbauer ${ }^{2,3}$, L. Heuser ${ }^{3}$ and W. Gehlen ${ }^{2}$
}

${ }^{1}$ Physiological Psychology, University of Bielefeld, D-33501 Bielefeld, Germany, ${ }^{2}$ University Clinic of Neurology, and ${ }^{3}$ University Clinic of Radiology, Knappschaftskrankenhaus Bochum-Langendreer, D-44892 Bochum, Germany, and ${ }^{4}$ Neurology Department, Kamillus-Clinic, D-53563 Asbach, Germany

Correspondence to: R. Babinsky, Neurology Department, Kamillus-Clinic, D-53563 Asbach, Germany

\begin{abstract}
The processing of episodic memories is believed to depend on the proper functioning of so-called bottleneck structures through which information apparently must pass in order to be stored long term. These regions are seen in the basal forebrain, the medial diencephalon, and the medial temporal lobe. We here report a case with circumscribed bilateral temporal lobe damage, principally involving the amygdaloid area. Neuropsychological investigation demonstrated preserved intelligence, intact general memory and several other undisturbed cognitive functions, but a specific, affect-related, memory disorder. We conclude from these findings that the role of the amygdala is to process mnemonic events in a way that a specific emotional significance can be found and reactivated. Therefore it is suggested that the amygdala is likely to be a bottleneck structure for affect-related long-term memory functions.
\end{abstract}

Keywords: Affect - Amygdala - Emotion - Information processing - Memory

The importance of the amygdaloid complex for long-term information processing has been an area of debate for many years. This started with the early work of Scoville and Milner (1957) who underemphasized the contribution of the amygdala in amnesia observed in cases after bilateral medial temporal lobe resections by arguing that "it is not known whether the amygdala plays any part in this mechanism [memory], since the hippocampal complex has not been removed alone, but always together with uncus and amygdala" (p. 21). The failure of early investigations to confirm an intimate relationship between medial temporal lobe damage and amnesia in non-human primates was attributed to the tasks used or to interspecies differences (Iversen, 1976; Weiskrantz, 1982). Mishkin (1978), who used a delayed non-match to sample task, demonstrated a severe memory deficit with combined, but not by separate lesions of amygdala and hippocampus. This result was confirmed in other studies (Zola-Morgan et al., 1982; Murray and Mishkin, 1985), but later Squire and Zola-Morgan (1991) questioned the view that the amygdala is important for mnemonic processing. Doty (1990) has also criticized the unreflected transfer of animal results onto those of human beings by, for example, arguing that H.M., Scoville and Milner's (1957) most famous amnesic, did not show any deficits in the tasks in which the monkeys of Mishkin (1978) had been severely disturbed (Freed et al., 1987). Lastly, in this sequence on evidence for and against the role of the amygdala in memory, Tranel and Hyman (1990) described the case of a young patient with selective bilateral amygdala damage and "a significant defect in visual, nonverbal memory" (p. 354). The authors concluded that their case "is consistent with the position that the amygdala is a crucial component of the neural substrate of memory in humans" (p. 355).

Views on the contribution of an individual brain structure to (long-term) memory processing are critically dependent on $(a)$ the measurements or test procedures applied, and (b) the underlying Weltanschauung one has about the brain's functioning in information processing. Furthermore, a distinction may be made between "a neuronal system which is involved in memory processing and a system which affects memory processes" (Gold et al., 1975 , p. 104). We will comment on variables $(a)$ and $(b)$. (a) For the amygdala as a strong relay of emotionally (affective) weighted information, the significance and rel- 


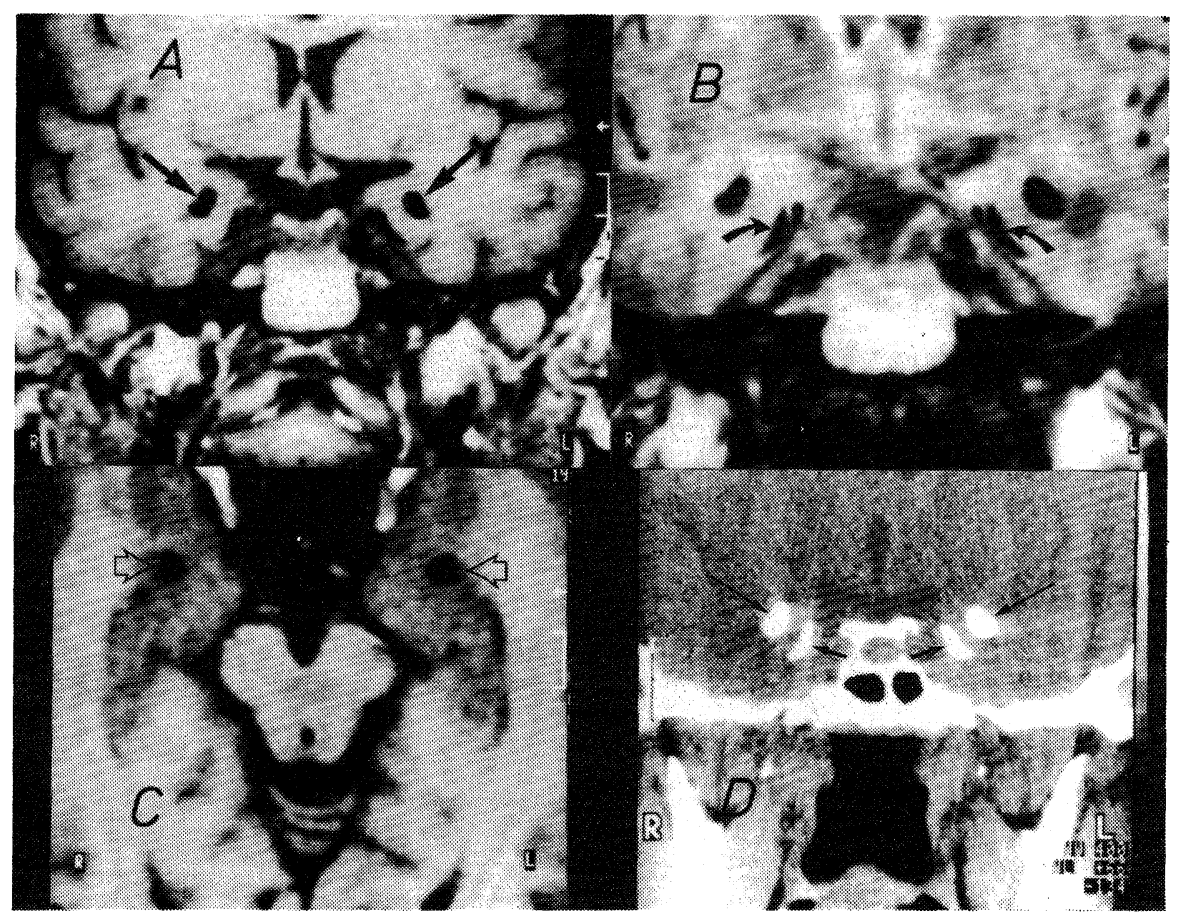

FIG. 1. Bilateral amygdaloid damage. (A) T1-weighted MRI (SE 650/30) shows oval hypotense lesions in the amygdala (arrows). (B) PD-weighted MRI (SE 2500/20) demonstrates lesions in the anteromesial cortex of the temporal lobe, the periamygdaloid gyrus (curved arrows). (C) T1-weighted MRI (SE 422/21), the amygdala lesions can be recognized in the axial scan (open arrows). (D) Coronal CT scan verifies the mineralization of the lesion in the amygdala (long arrows) and anteromesial cortex of the temporal lobe (short arrows).

evance of learning on the individual's subjective feeling may be a crucial determinant for its involvement. Tasks with "standard" associations will consequently depend much less on the amygdala's filtering and selection processes than emotionally colorful ones. Furthermore, Tranel and Hyman (1990) hypothesized that it may have a more crucial role in non-verbal, visuospatial memory than in verbal memory. (b) Whether one sees the mechanism of encoding as dependent on a largely hierarchically arranged array of individually active structures, or whether one adheres to a more dynamic view involving multiple interwoven and interacting nets (with still some crucial "bottleneck structures" existing), of cause, largely determines the conclusions one will draw from brain damage-behavior relations.

The appearance of selective bilateral amygdaloid damage in human cases is rare. We found it in a 39-year-old female patient suffering from Urbach-Wiethe disease (lipoid proteinosis), an uncommon, hereditary, systemic disorder characterized by the deposition of hyaline material in the skin and mouth-larynx areas. As is not uncommon in patients with this disease (Emsley and Paster, 1985; Newton et al., 1971), our patient had in addition a mineralization in the medial temporal lobe region which was bilaterally confined to the amygdaloid region, as has been found in previous cases (Fig. 1). In addition to neurological and neuroradiological assessment, the patient was examined neuropsychologically. These tests (described in more detail in Markowitsch et al., 1993) assessed attention and concentration, intelligence, learning, short- and longterm memory, verbal and figural-spatial memory, retrograde memory, concept formation, cognitive flexibility, and affect. A number of tests revealed normal functions, including those evaluating attention (ConcentrationEndurance Test d2; Brickenkamp, 1981), concentration (Trail Making Test), intelligence (IQ $=109$; reduced Wechsler Adult Intelligence Test; Dahl, 1986), digit span (7), the Corsi block tapping test (4), a German language form of the Rivermead Behavioral Memory Test (Wilson et al., 1985), the revised Wechsler Memory Scale (General Memory $=130$, Delayed Recall = 132; Wechsler, 1987), copy and recall condition of the Rey-Osterrieth Figure $($ copy $=36 / 36,100$ th percentile; 30 -min recall $=23 / 36$, 50th percentile; Lezak, 1983), the Wisconsin Card Sorting Test (11 categories, no errors at all), the Tower of Hanoi test with four discs ( 24 moves, no errors), the Concept Comprehension Task (concrete $=8 / 8$, abstract $7 / 8$; Cronin-Golomb, 1986), and the Gollin Incomplete Pic- 
tures Test (Henke et al., 1993). Also her remote memory abilities, tested with a German Famous Events Questionnaire and the Autobiographical Memory Interview (Kopelman et al., 1989), were normal.

On the other hand, significant abnormalities or defects were found in selective cognitive tasks: results from two personality questionnaires demonstrated heightened agitation and a tendency towards depression (Beck Depression Inventory: total $=28$; a German personality questionnaire showed deviant values in 5 of 12 dimensions). In the Rey Auditory Verbal Learning Task she was deficient and produced a reduced number of words in all trials (according to the norms of Wiens el al., 1988); e.g. trial 1: 4/15; trial 5: $10 / 15$; list B: $3 / 15$; recall: $7 / 15$. The same was true for another memory test battery with demanding time constraints [LGT-3 (Bäumler, 1974); Total Memory Score: 69, 2. percentile]. In the odor test (cf. von Cramon et al., 1993), in which six odors have to be associated with six nonsense drawings over six sessions (similar to the Visual Paired Associates paradigm of the revised Wechsler Memory Scale), her performance was in the lowest third. By the last two sessions she had learned only two associations, and this she did by verbally assigning those drawings as pungent and sweet which were related to the two most extreme odors.

In two tests in which recognition and priming of neutral versus emotional stimuli was evaluated, she demonstrated a clear dissociation in performance by memorizing neutral much better than emotional material: after the presentation of 12 emotional and 12 neutral words, her performance on a word stem completion task immediately and 1, 2 or 3 days after presentation was (\% correct): $50 \%, 16.7 \%$, $8.3 \%$ and $16.7 \%$ for emotional, and $66.7 \%, 83.3 \%, 66.7 \%$ and $41.7 \%$ for neutral words. In a picture recognition task 40 photographs were presented ( 20 neutral, 20 emotional pictures) and afterwards the patient recognized $85 \%$ neutral, but only $60 \%$ emotional pictures correctly. In this task, three matched controls identified $88.3 \%$ $($ S.D. $=10.4)$ neutral and $95 \%($ S.D. $=5)$ emotional photographs correctly.

We conclude from her performance in these tests-and from comparing it with that of a female patient with selective bilateral damage of the septal region and quite similar dissociations in memory (von Cramon et al., 1993)that the amygdala (and the septal nuclei) are structures which influence memory performance by selecting and filtering out information of different relevance to the individual. This mechanism makes the amygdala a nodal point in the circuitry of the brain implicated in long-term information processing. It underlines the view that certain bottleneck structures - of which the amygdala is oneact in a concerted and integrated way in memorizing declarative information. Förstl and Sahakian (1993) recently emphasized the cholinergic system as relevant in this respect, assuming the existence of a network composed of the basal forebrain, the amygdala and the orbitofrontal cortex.

\section{Acknowledgement}

While carrying out this study, R. Babinsky was supported by KOGNET/Ruhr-University Bochum.

\section{REFERENCES}

Bäumler G (1974) Lern- und Gedächtnistest LGT-3. Hogrefe, Göttingen.

Brickenkamp R (1981) Test d2, Aufmerksamkeits-BelastungsTest. Hogrefe, Göttingen.

Cronin-Golomb A (1986) Comprehension of abstract concepts in right and left hemispheres of complete commissurotomy patients. Neuropsychologia, 24, 881-887.

Dahl G (1986) WIP-Reduzierter Wechsler Intelligenztest. Hain, Meisenheim.

Doty RL (1990) Time and memory. In: Brain Organization and Memory: Cells, Systems and Circuits (Eds JL McGaugh, NM Weinberger and G Lynch), pp. 145-158. Oxford University Press, New York.

Emsley RA and Paster L (1985) Lipoid proteinosis presenting with neuropsychiatric manifestations. Journal of Neurology, Neurosurgery and Psychiatry, 48, 1290-1292.

Förstl H and Sahakian B (1993) Thalamic radiodensity and cognitive performance in mild and moderate dementia of the Alzheimer type. Journal of Psychiatry and Neuroscience, 18, 33-37.

Freed DM, Corkin S and Cohen NJ (1987) Forgetting in H.M.: a second look. Neuropsychologia, 25, 461-471.

Gold PE, Edwards RM and McGaugh JL (1975) Amnesia produced by unilateral, subseizure, electrical stimulation of the amygdala in rats. Behavioral Biology, 12, 95-105.

Henke K, Landis T and Markowitsch HJ (1993) Subliminal perception of pictures in the right hemisphere. Consciousness and Cognition, 2, in press.

Iversen SD (1976) Do hippocampal lesions produce amnesia in animals? International Review of Neurobiology, 19, 1-49.

Kopelman MD, Wilson BA and Baddeley A (1989) The Autobiographical Memory Interview: a new assessment of autobiographical and personal semantic memory in amnesic subjects. Journal of Clinical and Experimental Neuropsychology, 11, 724-744.

Lezak MD (1983) Neuropsychological assessment, 2nd edn. Oxford University Press, New York.

Markowitsch HJ, von Cramon DY and Schuri U (1993) Mnestic performance profile of a bilateral diencephalic infarct patient with preserved intelligence and severe amnesic disturbances. Journal of Clinical and Experimental Neuropsychology, 15, 627-652.

Mishkin M (1978) Memory in monkeys severely impaired by combined but not separate removal of amygdala and hippocampus. Nature, 273, 297-298.

Murray EA and Mishkin M (1985) Amygdalectomy impairs crossmodal association in monkeys. Science, 228, 604-606.

Newton FH, Rosenberg RN, Lampert PW and O'Brien JS (1971) Neurologic involvement in Urbach-Wiethe's disease (lipoid proteinosis). Neurology, 21, 1205-1213.

Scoville WB and Milner B (1957) Loss of recent memory after bilateral hippocampal lesions. Journal of Neurology, Neurosurgery and Psychiatry, 20, 11-21. 
Squire LR and Zola-Morgan S (1991) The medial temporal lobe memory system. Science, 253, 1380-1386.

Tranel D and Hyman BT (1990) Neuropsychological correlates of bilateral amygdala damage. Archives of Neurology, 47, 349-355.

von Cramon DY, Markowitsch HJ and Schuri U (1993) The possible contribution of the septal region to memory. Neuropsychologia, in press.

Wechsler D (1987) Wechsler Memory Scale-revised. Psychological Corporation, New York.

Weiskrantz L (1982) Comparative aspects of studies in amnesia. Philosophical Transactions of the Royal Society, London B, 298, 97-109.
Wiens AN, McMinn MR and Crossen JR (1988) Rey AuditoryVerbal Learning-Test: development of norms for healthy young adults. The Clinical Neuropsychologist, 2, 67-87.

Wilson BA, Cockburn J and Baddeley AD (1985) The Rivermead Behavioral Memory Test. Thames Valley Test Corp., Reading.

Zola-Morgan S, Squire LR and Mishkin M (1982) The neuroanatomy of amnesia: amygdala-hippocampus versus temporal stem. Science, 218, 1337-1339.

(Received 30 July 1993; accepted 10 August 1993) 


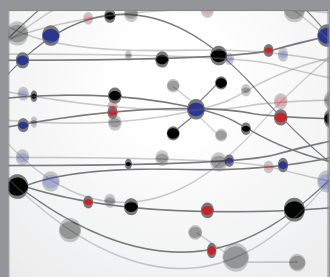

The Scientific World Journal
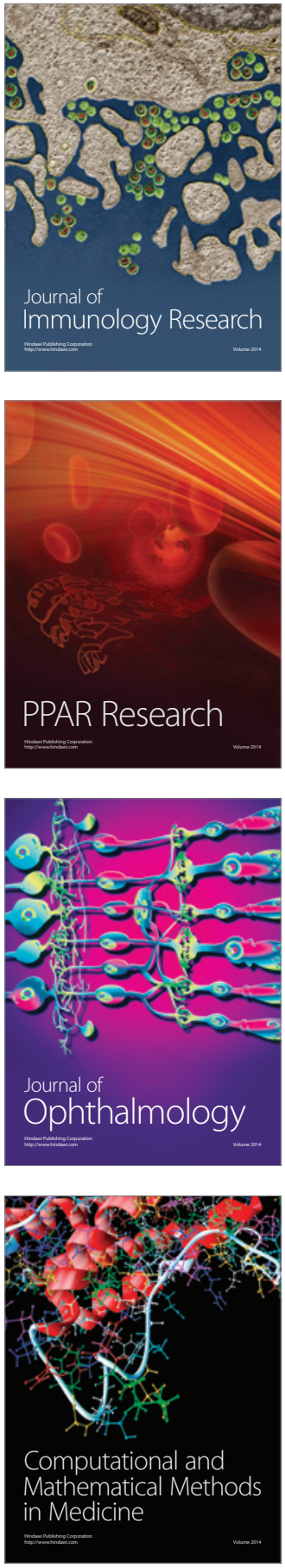

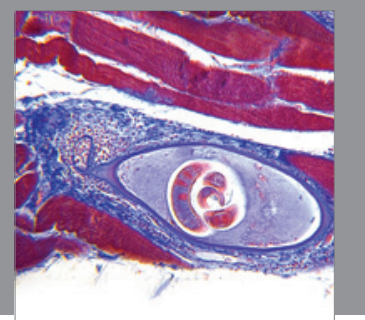

Gastroenterology

Research and Practice
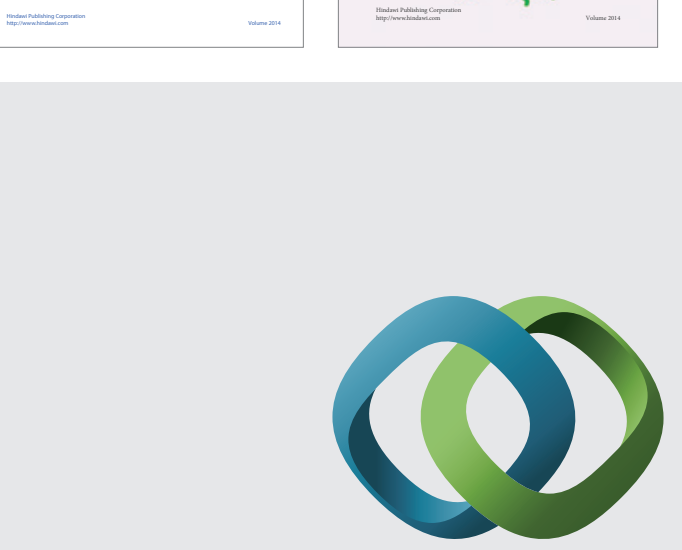

\section{Hindawi}

Submit your manuscripts at

http://www.hindawi.com
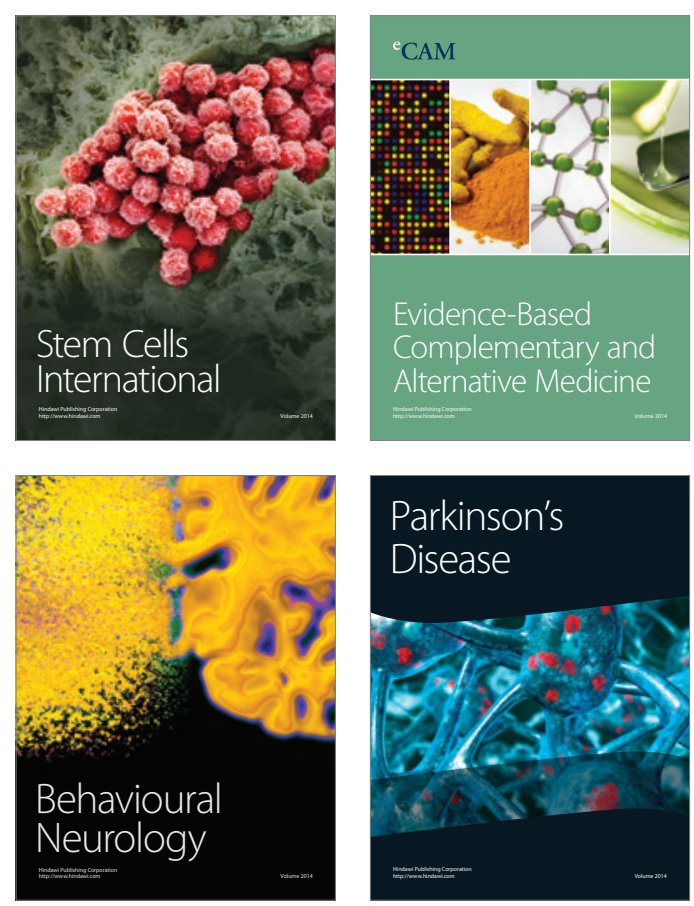

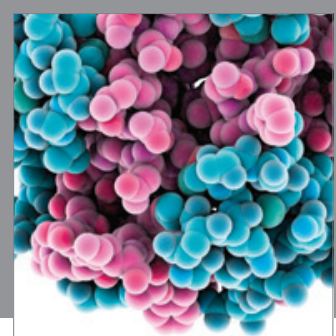

Journal of
Diabetes Research

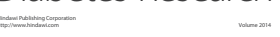

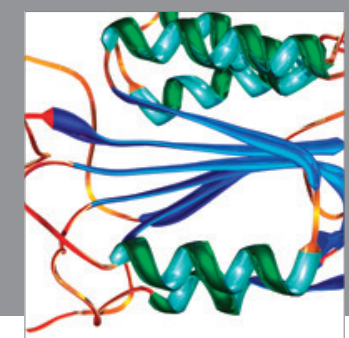

Disease Markers
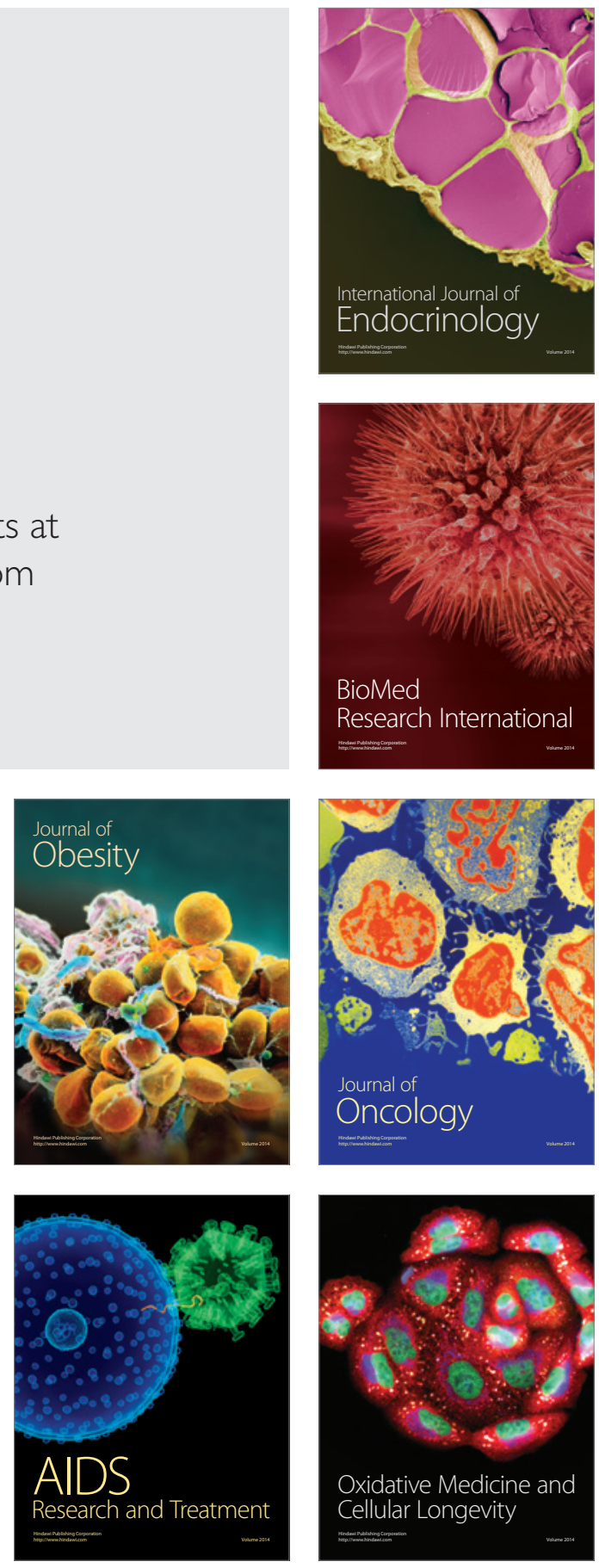